\title{
A prospective investigation of developmental trajectories of psychosocial adjustment in adolescents facing a chronic condition - study protocol of an observational, multi-center study
}

Petra Warschburger ${ }^{1 *}$ (D), Ann-Christin Petersen ${ }^{1}$, Roman E. von Rezori ${ }^{1}$, Friederike Buchallik ${ }^{1}$, Harald Baumeister ${ }^{2}$, Reinhard W. Holl ${ }^{3}$, Kirsten Minden ${ }^{4,5}$, Annabel S. Müller-Stierlin ${ }^{6}$, Christina Reinauer ${ }^{7}$, Doris Staab ${ }^{8}$ and COACH consortium

\begin{abstract}
Background: Relatively little is known about protective factors and the emergence and maintenance of positive outcomes in the field of adolescents with chronic conditions. Therefore, the primary aim of the study is to acquire a deeper understanding of the dynamic process of resilience factors, coping strategies and psychosocial adjustment of adolescents living with chronic conditions.

Methods/design: We plan to consecutively recruit $N=450$ adolescents (12-21 years) from three German patient registries for chronic conditions (type 1 diabetes, cystic fibrosis, or juvenile idiopathic arthritis). Based on screening for anxiety and depression, adolescents are assigned to two parallel groups - "inconspicuous" (PHQ-9 and GAD-7 < 7) vs. "conspicuous" (PHQ-9 or GAD-7 $\geq 7$ ) - participating in a prospective online survey at baseline and 12-month follow-up. At two time points (T1, T2), we assess (1) intra- and interpersonal resiliency factors, (2) coping strategies, and (3) health-related quality of life, well-being, satisfaction with life, anxiety and depression. Using a cross-lagged panel design, we will examine the bidirectional longitudinal relations between resiliency factors and coping strategies, psychological adaptation, and psychosocial adjustment. To monitor Covid-19 pandemic effects, participants are also invited to take part in an intermediate online survey.
\end{abstract}

Discussion: The study will provide a deeper understanding of adaptive, potentially modifiable processes and will therefore help to develop novel, tailored interventions supporting a positive adaptation in youths with a chronic condition. These strategies should not only support those at risk but also promote the maintenance of a successful adaptation.

Trial registration: German Clinical Trials Register (DRKS), no. DRKS00025125. Registered on May 17, 2021.

Keywords: Chronic conditions, Adolescents, Prospective, Quality of life, Resiliency, Coping, Protective factors, Type 1 diabetes, Juvenile idiopathic arthritis, Cystic fibrosis

\footnotetext{
* Correspondence: warschb@uni-potsdam.de

'Department of Psychology, Counseling Psychology, University of Potsdam,

Karl-Liebknecht-Str. 24-25, 14476 Potsdam, Germany

Full list of author information is available at the end of the article
}

C C The Author(s). 2021 Open Access This article is licensed under a Creative Commons Attribution 4.0 International License, which permits use, sharing, adaptation, distribution and reproduction in any medium or format, as long as you give appropriate credit to the original author(s) and the source, provide a link to the Creative Commons licence, and indicate if changes were made. The images or other third party material in this article are included in the article's Creative Commons licence, unless indicated otherwise in a credit line to the material. If material is not included in the article's Creative Commons licence and your intended use is not permitted by statutory regulation or exceeds the permitted use, you will need to obtain permission directly from the copyright holder. To view a copy of this licence, visit http://creativecommons.org/licenses/by/4.0/ The Creative Commons Public Domain Dedication waiver (http://creativecommons.org/publicdomain/zero/1.0/) applies to the data made available in this article, unless otherwise stated in a credit line to the data. 


\section{Background}

Having a chronic condition (CC) means facing an additional stressor in life. Especially during adolescence, youths are confronted with a range of developmental tasks, e.g., finding a partner, preparing for future family and work life, accepting their own body, which can strongly interfere with the demands of a CC [1]. There is consistent evidence that facing a $\mathrm{CC}$, irrespective of the specific diagnosis, increases the risk for mental health problems, such as anxiety and depression [2, 3]. But focusing only on mental disorders does, on the one hand, not cover the entire spectrum of potential functional limitations experienced in daily life. On the other hand, it neglects potential successful psychosocial adjustment. Including health-related quality of life (HRQoL) as a multifaceted, subjective indicator overcomes these shortcomings and allows getting a more concise picture of the psychosocial situation of these youths. Numerous studies have shown that HRQoL in chronically ill children and adolescents is impaired with small to moderate effect sizes compared to healthy youths [4-6]. Yet, CC as a risk factor is not inevitably associated with a poor adjustment. Considerable interindividual differences can be observed and it seems that the predominant response to the CC is a good adjustment [7]. This leads not only to the question of which characteristics and which processes are involved in maladjustment but also to the question of how to explain and attain a good adjustment. Up to now, the majority of research aims to explain the adverse outcomes and little is known about the emergence and maintenance of positive outcomes in the field of CC. There is evidence that higher age, being female, and higher $\mathrm{CC}$ severity are significantly associated with worse HRQoL [4-6] and increased mental health problems [8-10]. These factors only explain a small proportion of the variance, whereas psychological factors, e.g., coping or self-esteem, play a more significant role $[1,3$, 7, 11-13]. Within the resilience-in-illness and the positive development framework, a number of resiliency factors, primarily addressed in the context of protective factors in CCs, promote positive adjustment via enhancing positive coping strategies and minimizing the influence of risk factors $[14,15]$. Hereby, resiliency refers to the "... ability to cope with life circumstances in a positive way, even under conditions overshadowed by risk, and to develop appropriate coping skills despite unfavorable circumstances" ([16], p. 127). In the context of a CC, high levels of self-esteem, optimism, or self-efficacy proved to be relevant resiliency attributes [14, 17-19]. In addition, the so-called "secondary coping strategies" (focusing on efforts to adapt to the CC), e.g., acceptance, cognitive restructuring, or positive thinking, are considered beneficial $[11,20,21]$. It is well-known that resiliency and coping vary with developmental stage $[11,22]$ and there is first evidence for a dynamic and reciprocal relationship with HRQoL and mental disorders [23]. To sum up, prospective cohort designs are needed to understand the dynamic nature of adjustment in youths with a $\mathrm{CC}$ since outcomes as well as its protective and risk factors are not stable but fluctuate over time [11]. In addition, it is necessary to include sensitive developmental transition periods (entry into adolescence; emerging adulthood) with their manifold changes [11].

\section{Objectives}

The primary aim of the project is to get a deeper understanding of the dynamic process of psychosocial adaptation, including intra- and interpersonal resiliency and coping strategies, in the face of CCs in a group of adolescents (12-21 years) with type 1 diabetes, cystic fibrosis, and juvenile arthritis. Hereby, psychosocial adaptation refers to the process of adaptation, while psychosocial adjustment refers to the outcome of this adaptation process $[13,24]$. The research questions (Q) and hypotheses are as follows:

Q1. How is the causal relationship between a) resiliency and coping strategies; b) psychosocial adaptation and adjustment? It is hypothesized that resiliency and coping strategies show reciprocal influences, and both precede the psychosocial adjustment.

Q2. Does psychosocial adaptation (e.g., resilience factors and coping strategies) play a significant role in psychosocial adjustment beyond the influence of general demographic and CC-related factors? It is hypothesized that psychosocial adaptation is more important in explaining adjustment than the abovementioned general factors (e.g., age, CC severity, gender). It is further assumed that females, as well as those showing conspicuous mental health screening, exhibit lower scores in psychosocial adjustment and therefore represent a high-risk group.

Q3. Depending on general, demographic, and CCrelated factors, do adolescents differ in psychosocial adaptation and adjustment? It is hypothesized that adolescents with higher age, female gender, more severe mental health problems and higher $\mathrm{CC}$ severity exhibit lower scores in psychosocial adaptation and adjustment.

Q4. Depending on general, demographic, and CCrelated factors, do adolescents differ in their course of psychosocial adaptation and adjustment over the oneyear follow-up period? It is hypothesized that adolescents with higher age, female gender, more severe mental health problems and higher $\mathrm{CC}$ severity show a less favorable course of adaptation over the 1-year followup period compared to those with younger age, male 
gender, less severe mental health problems and lower $\mathrm{CC}$ severity. Figure 1 displays the conceptual model of the study.

\section{Methods/design}

\section{Study design}

This prospective observational study is part of a consortium (Chronic Conditions in Adolescents: Implementation and Evaluation of Patient-centered Collaborative Healthcare $(\mathrm{COACH}))$ funded by the German Federal Ministry of Education and Research (no. 01GL1740C) that examines the mental health status of adolescents with a CC and examines different approaches to understand and overcome mental health issues [25, 26]. The study received approval by the Ethics Committee of the University of Potsdam (date 02/02/2018, no. 52/2017; date $08 / 31 / 2018$, no. $37 / 2018$; date $10 / 22 / 2018$, reference no. 37/2018). Assessments take place starting with the mental health screening in clinical units, followed by two assessment time points over 1 year if adolescents agree to participate in the study: baseline (T1) and 12 months follow-up (T2). Based on the mental health screening for anxiety and depression, participants are assigned into the two parallel groups "inconspicuous" with scores below the cut-off (GAD-7 and PHQ-9 $<7$ ) and "conspicuous" with scores above the cut-off (GAD-7 or PHQ-9 $\geq 7$ ) [27-31]. During the recruitment we have been confronted with the Covid-19 pandemic and several regulations to contain the spread of the SARS-CoV2 coronavirus. Therefore, we included an additional online survey to monitor the Covid-19 pandemic effects. The Covid-19-specific study received approval by the Ethics Committee of the University of Potsdam (date 04/ 29/2020, no. 27/2020; date 06/26/2020, reference no. 48 / 2020). The intermediate Covid-19-specific online survey was first implemented in April 2020 and sent out to all participants that had been included into the study up to this point. Since then, the questionnaire has been being sent to participants consecutively 1 week after completing the questionnaire at baseline (T1). The flow chart of the study design is shown in Fig. 2.

\section{Study participants}

Adolescents between 12 and 21 years with type 1 diabetes, cystic fibrosis, or juvenile idiopathic arthritis are eligible for inclusion.

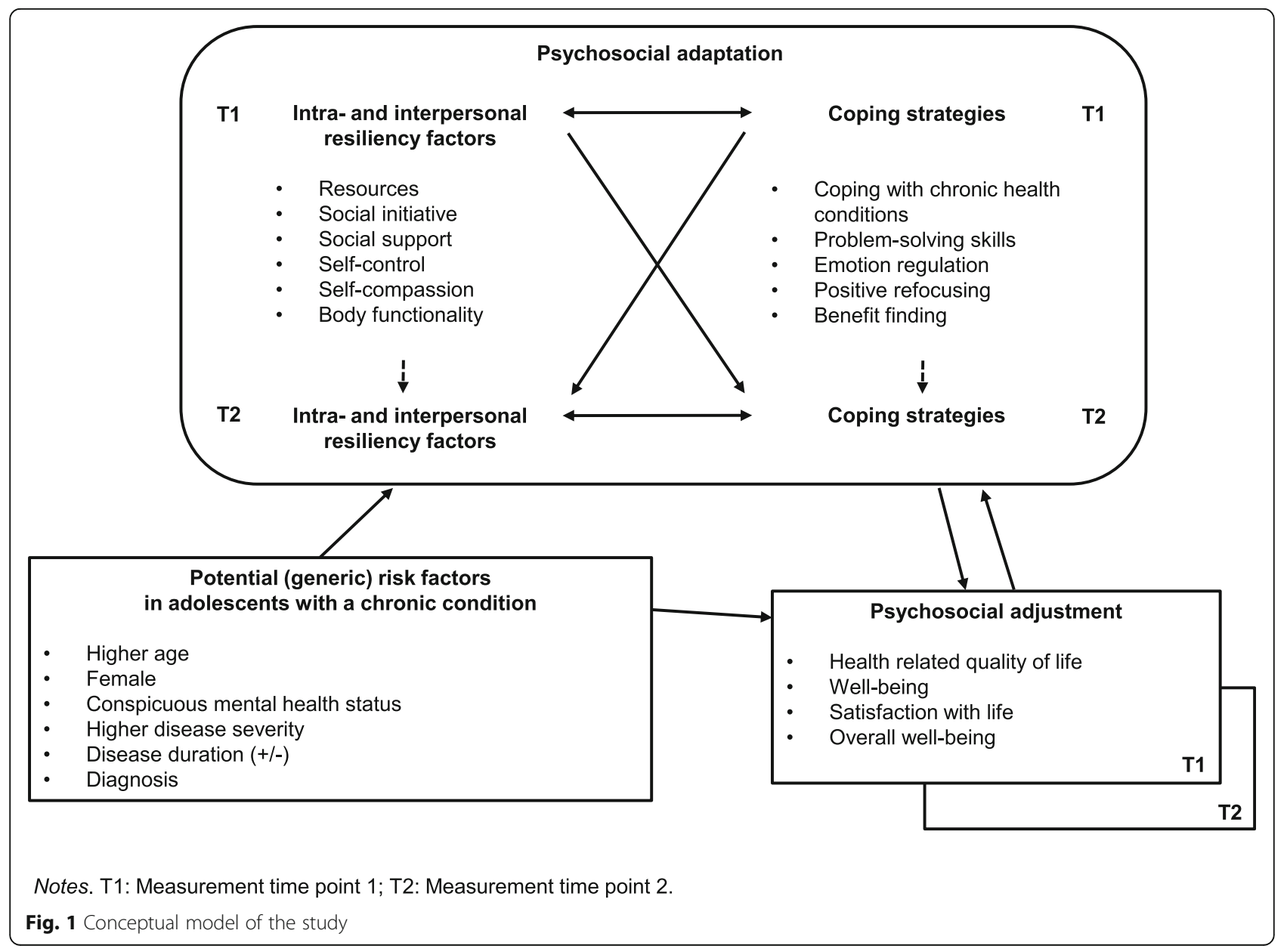




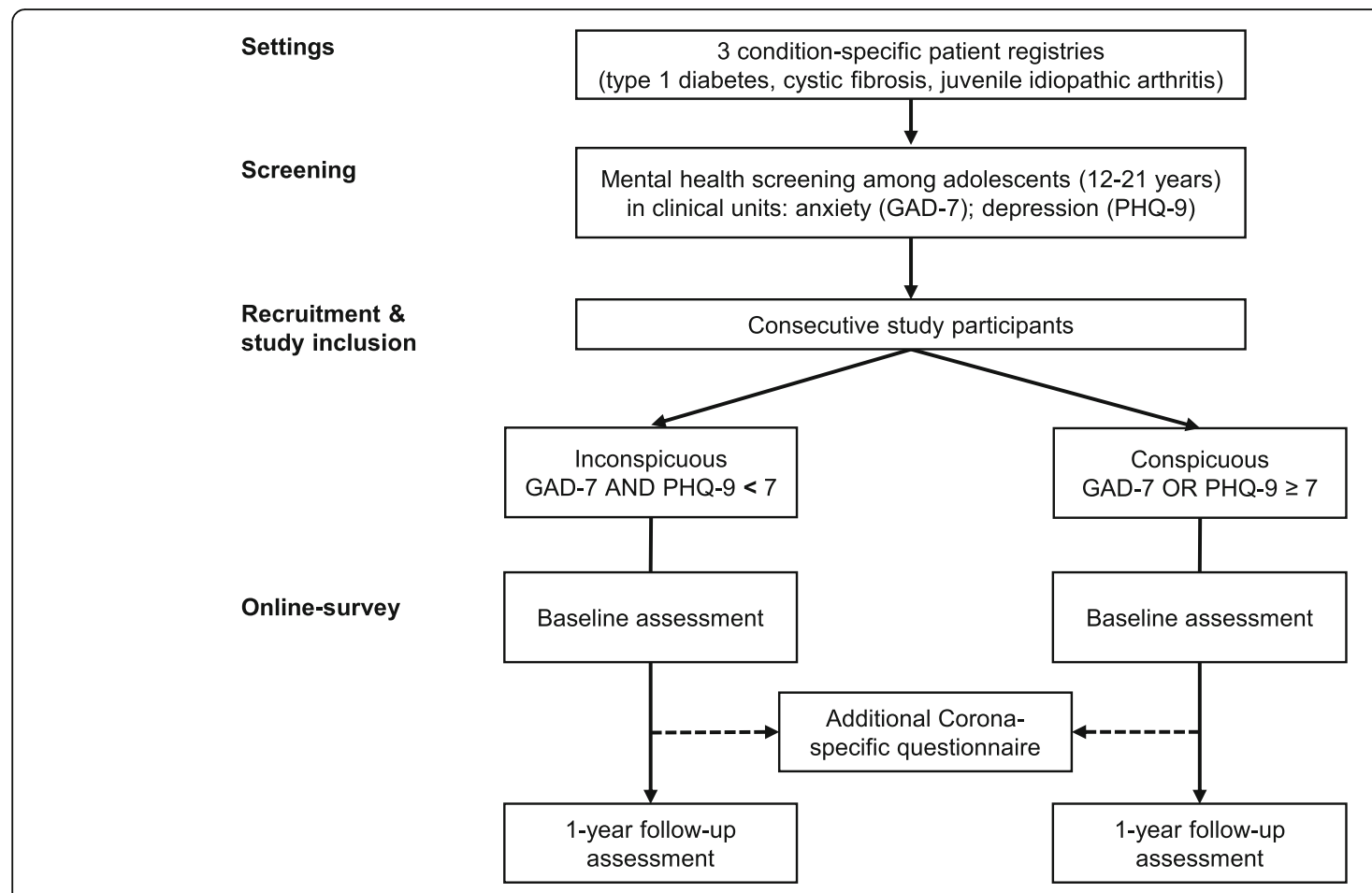

Notes. GAD-7: General anxiety disorder-scale; PHQ-9: Patient health questionnaire.

Fig. 2 Study flow chart

\section{Recruitment}

Consecutive recruitment for this ongoing trial started in June 2019 in clinical centres. Adolescents with type 1 diabetes, cystic fibrosis, or juvenile idiopathic arthritis are recruited during their regular check-up visits in hospitals, clinics, medical practices, and medical centres across Germany. These clinical institutions all take part in one of the following German patient registries, the National Paediatric Rheumatologic Database (NPRD) [32], the National Diabetes Registry (DPV) [33], or the Cystic Fibrosis (CF) Registry [34]. Eligible patients (and their parents) are informed about the research project by the treating physician at the clinical centre and eligible patients are screened for anxiety and depression. All participants and parents of participants under legal age (<18 years) provide written informed consent prior to inclusion into the study. Informed consent is sent to the University of Potsdam and all further recruitment activities are conducted by researchers there. In the next step, participants are invited to take part in the prospective online survey, which means that they are contacted by phone and receive an invitation email with the link to the survey. If they do not complete the questionnaire, they are contacted by email and phone at set time intervals and reminded to participate. Furthermore, they receive monthly SMS greetings to increase study adherence. To monitor the Covid-19 pandemic effects, participants are invited to take part in an intermediate online survey. Survey data will be connected with the objective medical background data provided by the patient registries: diagnosis, $\mathrm{CC}$ severity, $\mathrm{CC}$ duration and $\mathrm{CC}$ specific data, e.g., hemoglobin A1c (HbA1c), forced expiratory volume in $1 \mathrm{~s}$ (FEV1), and clinical juvenile arthritis disease activity score (cJADAS). Principles of good research practice, data, and participants' privacy protection are strictly adhered to. For each successfully recruited participant, the respective clinical unit receives a financial compensation of $75 €$ for its recruitment effort. Participants receive gift coupons as compensation for their time at T1 (20€) and T2 (30€). The online survey started in August 2019 and has been recruiting participants consecutively since. See Table 1 for preliminary descriptive data on the sample.

\section{Study measures}

The comprehensive assessment in the observational study includes various psychological measures which are widely used in research. Unless otherwise stated, the name of each scale represents the underlying construct measured, with higher scores indicating more severe 
Table 1 Demographics of the preliminary sample

\begin{tabular}{|c|c|c|c|}
\hline Variables & $\begin{array}{l}\text { Total } \\
(n=426)\end{array}$ & $\begin{array}{l}\text { Inconspicuous } \\
(n=297)\end{array}$ & $\begin{array}{l}\text { Conspicuous } \\
(n=129)\end{array}$ \\
\hline \multicolumn{4}{|l|}{ Gender } \\
\hline Male & 185 & 141 & 44 \\
\hline Female & 240 & 155 & 85 \\
\hline Non-binary & 1 & 1 & 0 \\
\hline \multicolumn{4}{|l|}{ Age } \\
\hline$M(S D)$ & $15.41(2.05)$ & $15.36(2.03)$ & $15.53(2.11)$ \\
\hline Range & $12-21$ & $12-21$ & $12-21$ \\
\hline \multicolumn{4}{|c|}{ Subjective socioeconomic status ${ }^{a}$} \\
\hline$M(S D)$ & $6.73(1.38)$ & $6.92(1.39)$ & $6.30(1.27)$ \\
\hline Scale range ${ }^{b}$ & Middle range & Middle range & Middle range \\
\hline \multicolumn{4}{|l|}{ Chronic condition } \\
\hline Type 1 diabetes & 316 & 214 & 102 \\
\hline Cystic fibrosis & 28 & 21 & 7 \\
\hline Juvenile idiopathic arthritis & 82 & 62 & 20 \\
\hline
\end{tabular}

Note. M Mean; $n$ Number of participants; SD Standard deviation; Last day of data inclusion: 01/06/2021

a Missings: $n=16$

${ }^{\mathrm{b}}$ Scale ranges from 1 to 10

manifestations of the respective construct. Table 2 gives an overview over the study measures. References for study measures that have previously been published elsewhere are provided in the text (see Additional File 1 for self-constructed study measures).

\section{Assessment of adjustment: HRQoL and well-being}

Multiple indicators for the assessment of HRQoL and well-being are used.

\section{HRQoL}

HRQoL is one of the major outcomes in medical research and is measured by the German version of the DISABKIDS Chronic Generic Module (DCGM-37) [35]. The 37 items are allocated to three domains with two facets each: psychological (independence, emotions), social (social exclusion, social inclusion), and physical (physical limitations, treatment/medication). The items are measured on a 5-point Likert scale ranging from 1 "never" to 5 "always". A sample item is: "Do you have fun in your life?". Internal consistency of the subscales ranges from Cronbach's $\alpha=.70$ to Cronbach's $\alpha=.87$. Internal consistency for the total score is Cronbach's $\alpha=.93[35]$.

\section{Well-being}

The German version of the 5-item WHO-5 Well-Being Index (WHO-5) assesses overall well-being [36]. Children and adolescents are asked to report the presence of positive feelings in the last 2 weeks on a 6-point scale ranging from 1 "at no time" to 6 "all the time" (e.g., "I have felt calm and relaxed."). The WHO-5 can be validly administered to children and adolescents in pediatric care [37].

\section{Satisfaction with life}

The German version of the 5-item Satisfaction with Life Scale (SWLS) [38] is used to measure satisfaction with life (e.g., "I am satisfied with my life.") whereby the first two items are adapted in their wording to the age group. The items are measured on a scale ranging from 1 "low satisfaction" to 7 "high satisfaction". Internal consistency for the total score is Cronbach's $\alpha=.92$ [39].

\section{Overall well-being}

The Self-Assessment Manikin (SAM) is a picture-based assessment of affective reactions towards different stimuli $[40,41]$. The current study focuses on overall well-being. Participants are asked "How do you feel in general?" and have to choose one of the five manikins ranging from looking very unhappy to smiling brightly.

\section{Assessment of psychosocial adaptation: resources and coping strategies}

Multiple indicators for the assessment of psychosocial adaptation are used.

\section{Resources in childhood and youth}

Seven of the ten subscales of the Questionnaire of Resources in Childhood and Youth (FRKJ 8-16) are used to assess personal (empathy and perspective-taking, selfefficacy, self-esteem, optimism, and sense of coherence) 
Table 2 Study measures

\begin{tabular}{|c|c|c|}
\hline Study Measures & T1 & $\mathrm{T} 2$ \\
\hline \multicolumn{3}{|l|}{ Psychosocial adjustment } \\
\hline DISABKIDS Chronic Generic Module (DCGM-37) & $x$ & $x$ \\
\hline WHO-5 Well-Being Index (WHO-5) & $x$ & $x$ \\
\hline Satisfaction with Life Scale (SWLS) & $x$ & $x$ \\
\hline Self-Assessment Manikin (SAM) & $x$ & $x$ \\
\hline \multicolumn{3}{|l|}{ Psychosocial adaptation - Resources } \\
\hline Questionnaire of Resources in Childhood and Youth (FRK 8-16) & $x$ & $x$ \\
\hline Questionnaire of Social Competence in Children and Adolescents, subscale social initiative (FSK-KJ) & $x$ & $x$ \\
\hline Berlin Social Support Scales (BSSS), subscale seeking social support & $x$ & $x$ \\
\hline Self-Control Scale (SCS-K-D) & $x$ & $x$ \\
\hline Self-Compassion Scale (SCS-D short version) & $x$ & $x$ \\
\hline Functionality Appreciation Scale (FAS) & $x$ & $x$ \\
\hline \multicolumn{3}{|l|}{ Psychosocial adaptation - Coping strategies } \\
\hline Coping with Chronic Health Conditions Questionnaire (CODI) & $x$ & $x$ \\
\hline Questionnaire of Stress and Stress Management in Childhood and Adolescence (SSKJ 3-8), subscale problem-oriented coping & $x$ & $x$ \\
\hline Emotion Regulation Questionnaire (ERQ) & $x$ & $x$ \\
\hline Cognitive Emotion Regulation Questionnaire (CERQ), subscale positive refocusing & $x$ & $x$ \\
\hline Benefit Finding Scale for Children (BFSC) & $x$ & $x$ \\
\hline \multicolumn{3}{|l|}{ Generic risk factors - Psychopathology } \\
\hline Patient Health Questionnaire (PHQ-9) & $x^{a}$ & $x$ \\
\hline General Anxiety Disorder-Scale (GAD-7) & $x^{a}$ & $x$ \\
\hline \multicolumn{3}{|l|}{ Generic risk factors - Developmental tasks and stress } \\
\hline Questionnaire on Developmental Tasks in Adolescence & & $x$ \\
\hline Questionnaire on critical life events & & $x$ \\
\hline Perceived Stress Scale (PSS-4) & & $x$ \\
\hline Questionnaire on overall impact of the Covid-19 pandemic & & $x$ \\
\hline Generic risk factors - Sociodemographic and CC-specific information & $x$ & $x^{b}$ \\
\hline
\end{tabular}

Note. ${ }^{\mathrm{a}}$ Assessed in clinical centres; ${ }^{\mathrm{b}}$ Except age at diagnosis

and social resources (parental and social support, peer-group integration) in children and adolescents [42]. Each subscale contains six items. Participants' responses are measured on a scale ranging from 1 "never true" to 4 "always true". A sample item is: "When I set my mind to something, I get it done.". The reliability of the subscales ranges from Cronbach's $\alpha=.69$ to Cronbach's $\alpha=.89$ [42].

\section{Social initiative}

The Questionnaire of Social Competence in Children and Adolescents (FSK-KJ) is a multidimensional questionnaire to assess social competencies in children and adolescents [43]. The current study uses the subscale "social initiative" (Cronbach's $\alpha=.83$ ) [43]. The subscale contains eight items with a response format ranging from 1 "not at all applicable" to 5 "absolutely applicable". A sample item is: "I make friends easily.".

\section{Seeking social support}

The Berlin Social Support Scales (BSSS) were developed in the context of coping with illness and measure social support on multiple dimensions [44]. The 5-item subscale "seeking social support" is used whereby participants rate how much the presented statements regarding support seeking apply to them on a scale ranging from 1 "strongly disagree" to 4 "strongly agree" (e.g., "When I have concerns, I seek out a conversation."). In addition, the source of support is assessed by presenting a list of possible sources of support (e.g., parents, relatives, friends, teachers, etc.). Internal consistency of the total score is Cronbach's $\alpha=.81$ [44].

\section{Self-control}

The German version of the 13-item Self-Control Scale (SCS-K-D, short version) is used to assess dispositional self-regulatory behaviors (e.g., "I am good at resisting 
temptation.") [45]. Items are scored on a 5-point Likert scale, ranging from 1 "not at all like me" to 5 "very much like me". Internal consistency for the total score is Cronbach's $\alpha=.79$ [45].

\section{Self-compassion}

The German version of the Self-Compassion Scale (SCS$\mathrm{D}$, short version) encompasses 12 items rated on a 5point scale, ranging from 1 "almost never" to 5 "almost always" [46] and comprises six subscales: self-kindness, self-judgment, common humanity, isolation, mindfulness, over-identification. A sample item is: "I try to be understanding and patient towards those aspects of my personality I don't like.". Internal consistency for the subscales ranges from Cronbach's $\alpha=.54$ to Cronbach's $\alpha=.75$ (total score: Cronbach's $\alpha=.86$ ) [47].

\section{Body functionality}

The German version of the 7-item Functionality Appreciation Scale (FAS) is used to assess body functionality [48]. Participants indicate their appreciation of body functionality on a 5-point Likert scale ranging from 1 "strongly disagree" to 5 "strongly agree" (e.g., "I appreciate my body for what it is capable of doing."). Internal consistency for the FAS score is Cronbach's $\alpha=.86$ [48].

\section{Coping with chronic health conditions}

The German version of the 29-item Coping with Chronic Health Conditions Questionnaire (CODI) is used to assess coping strategies of children and adolescents with CCs [49]. The CODI comprises six domains: acceptance, avoidance, cognitive-palliative, distance, emotional reaction, and wishful thinking. Participants indicate their use of the coping strategies on a 5 -point Likert scale ranging from 1 "never" to 5 "all the time" (e.g., "I try to ignore my illness."). Depending on the domain, the internal consistency of the questionnaire ranges from Cronbach's $\alpha=.69$ to Cronbach's $\alpha=.83$ [49].

\section{Problem-solving skills}

Problem-solving skills are measured by the 6-item subscale "problem-oriented coping" of the Questionnaire of Stress and Stress Management in Childhood and Adolescence (SSKJ 3-8) [50]. The wording of the instruction was adapted to the specific CC context. Items are scored on a 5 -point Likert scale, ranging from 1 "never" to 5 "always". A sample item is: "I then decide on a way to solve the problem". The internal consistency for the subscale is Cronbach's $\alpha=89$ [50].

\section{Emotion regulation}

The German version of the 10-item Emotion Regulation Questionnaire (ERQ) is used to assess the habitual use of two emotion regulation strategies: cognitive reappraisal (6 items) and expressive suppression (4 items) [51]. Items are scored on a 7-point Likert scale, ranging from 1 "strongly disagree" to 7 "strongly agree". A sample item is: "I keep my emotions to myself". The subscales of the ERQ show an internal consistency of Cronbach's $\alpha=.76$ for the subscale "cognitive reappraisal" and Cronbach's $\alpha=.74$ for the subscale "expressive suppression" [51].

\section{Positive refocusing}

The Cognitive Emotion Regulation Questionnaire (CERQ) consists of nine subscales, each referring to what someone thinks after the experience of threatening or stressful events [52]. This study uses the German version of the 3-item subscale "positive refocusing "(e.g., "I think of pleasant things that have nothing to do with it."). Participants indicate on a 5-point Likert scale ranging from 1 "(almost) never" to 5 "(almost) always" how much they rely on positive refocusing. The internal consistency of the subscale is Cronbach's $\alpha=.85$ [53].

\section{Benefit finding}

A German version of the 10-item Benefit Finding Scale for Children (BFSC) is used to assess benefit finding [54]. Participants indicate the extent to which their illness has helped them grow personally (e.g., "Has helped me to become a stronger person."). Their responses are measured on a 5-point scale ranging from 1 " not at all true for me" to 5 "very true for me". The BFSC has an internal consistency of Cronbach's $\alpha=.83$ [54].

\section{Assessment of psychopathology}

Additional instruments were used at T2, including the PHQ-9 and the GAD-7 from the mental health screening in the clinical centres to assess development of mental health of the participants.

\section{Depression}

The German version of the 9-item Patient Health Questionnaire (PHQ-9) is administered as a screening inventory to detect depressive symptoms within the past 2 weeks (e.g., "Little interest or pleasure in doing things.") [55]. We omitted one item assessing suicidal ideation. Responses are measured on a 4-point Likert scale ranging from 0 "not at all" to 3 "nearly every day". The computerized version of the PHQ-9 has an internal consistency of Cronbach's $\alpha=.88$ [56].

\section{Anxiety}

The German version of the General Anxiety DisorderScale (GAD-7) is administered to detect symptoms of anxiety within the past 2 weeks (e.g., "Feeling nervous, anxious or on edge.") $[57,58]$. The GAD-7 consists of 
seven items with a 4-point Likert scale ranging from 0 "not at all" to 3 "nearly every day". The GAD-7 shows an internal consistency of Cronbach's $\alpha=.79$ to Cronbach's $\alpha=.91$ [59] and successful usage in adolescents is reported [60, 61].

\section{Assessment of developmental tasks and stress}

Multiple indicators for the assessment of developmental tasks and stress are used.

\section{Developmental tasks}

A modified version of the Questionnaire on Developmental Tasks in Adolescence is administered to assess normative developmental tasks in youth [62]. For the current study, the questionnaire was shortened to eleven items and the wording was adapted to the targeted age group. Participants indicate their subjective importance of the presented developmental tasks on a 6-point Likert scale ranging from 1 "not (yet) important" to 6 "no longer important" (e.g., become more independent from parents, accepting changes in the body and one's appearance). Participants also mark on a line where they are in the process of completing each developmental task.

\section{Critical life events}

A self-constructed 10-item questionnaire assesses critical life events that occurred in participants' life during the past 12 months (e.g., "Did you move out of your parents' house?"). If participants select one or more of the events, they are asked to indicate how each of them has impacted their lives on a slider ranging from 0 "not at all" to 100 "completely". Additionally, an open format question asks for further potential life events not covered by the items presented.

\section{Perceived stress}

The German version of the 4-item Perceived Stress Scale (PSS-4) is used to assess the frequency of perceived stress in the past 12 months (e.g., "In the last twelve months, how often have you felt that you were unable to control the important things in your life?") [63]. The items are measured on a 5-point Likert scale ranging from 1 "never" to 5 "very often". The internal consistency is Cronbach's $\alpha=.72$ [63].

\section{Overall impact of the Covid-19 pandemic}

A self-constructed 4-item Covid-19-specific scale is administered to assess the impact of the Covid-19 pandemic on different life domains: family life, education, interaction with friends and leisure activities. Participants use a slider to indicate how much each of these life domains has changed as a result of the Covid-19 pandemic on a scale ranging from 0 "not at all" to 100 "completely".

\section{Sociodemographic and CC-specific information}

Sociodemographic information collected in the study comprise gender, age, body size and weight, living situation, and education as self-assessments [64]. Subjective socioeconomic status is assessed by a slightly modified version of the MacArthur Scale [65]. CC-specific variables encompass the $\mathrm{CC}$ itself, age at diagnosis, further physical and mental disorders, psychological treatment, subjective severity of the $\mathrm{CC}$, subjective health status using three items that were developed based on widely used measures [66, 67], as well as satisfaction with treatment staff and identification with the group of people who have the same CC [68].

\section{Covid-19 monitoring}

In reaction to the Covid-19 pandemic, the additional online survey contains questions regarding psychosocial adjustment and adaptation as well as risk perception, emotions, psychological distress and the impact of the Covid-19 pandemic. Established instruments, as well as self-constructed Covid-19-specific instruments, are used for this purpose (see Table 3 for an overview and Additional file 2 for detailed information on the Covid-19 specific measures).

\section{Sample size}

The sample size for the prospective analysis is determined by the main and most complex analysis applying latent structural equation modeling (SEM). Up to now, there is no unambiguous rule on required sample sizes in SEM, as it is dependent on several aspects (e.g., model complexity, data distribution, amount of missing data, effect size, and number of parameters that have to be computed). As a rule of thumb, the sample size should not be lower than 200 although computations should be possible with sample sizes greater than 100 [69]. As a multi-group latent SEM (grouping factor: mental health status inconspicuous vs. conspicuous) should be applied to the data, a total sample size of 400 should be sufficient. Both the inconspicuous and the conspicuous group should consist of a minimum of 100 participants. Therefore, at least 200 participants in each group should be achieved. However, regarding the prevalence of depression and anxiety in youth with CCs, while considering possible barriers to participate with symptoms of depression and/or anxiety, we expect a higher amount of inconspicuous participants. To reduce bias in estimates obtained, which may occur due to non-random differences in covariates between groups, we will consider appropriate matching procedures. Therefore, we increased the targeted sample size for the inconspicuous group to 250 participants during the recruitment process. 
Table 3 Study measures for intermediate Covid-19 study

\begin{tabular}{|c|c|}
\hline Study Measures & Covid-19 study \\
\hline \multicolumn{2}{|l|}{ Psychosocial adjustment } \\
\hline WHO-5 Well-Being Index (WHO-5) & $x^{a}$ \\
\hline Satisfaction with Life Scale (SWLS) & $x^{a}$ \\
\hline \multicolumn{2}{|l|}{ Psychosocial adaptation - Resources } \\
\hline Questionnaire of Resources in Childhood and Youth (FRK 8-16), subscale peer-group integration & $x$ \\
\hline Berlin Social Support Scales (BSSS), subscale seeking social support & $x^{b}$ \\
\hline \multicolumn{2}{|l|}{ Psychosocial adaptation - Coping strategies } \\
\hline Benefit Finding Scale for Children (BFSC) & $x^{b}$ \\
\hline \multicolumn{2}{|l|}{ Covid-19-specific resources } \\
\hline Self-efficacy beliefs & $x$ \\
\hline Outcome expectations & $x$ \\
\hline Resilience & $x$ \\
\hline Contact to peers & $x$ \\
\hline Social norms & $x$ \\
\hline \multicolumn{2}{|l|}{ Covid-19-specific coping strategies } \\
\hline Coping across Situations Questionnaire (CASQ) & $x^{b}$ \\
\hline Preparedness & $x$ \\
\hline Risk perception & $x$ \\
\hline \multicolumn{2}{|l|}{ Emotions and psychological distress during the Covid-19 pandemic } \\
\hline Positive and Negative Affect Schedule (PANAS) & $x$ \\
\hline Perceived Stress Scale (PSS-4) & $x$ \\
\hline Emotions & $x$ \\
\hline General questions regarding the Covid-19 pandemic & $x$ \\
\hline Overall impact of the Covid-19 pandemic & $x^{c}$ \\
\hline
\end{tabular}

Note. ${ }^{\mathrm{a} A s}$ used in $\mathrm{T} 1$ and T2. ${ }^{\mathrm{b}}$ Adapted to Covid-19 pandemic situation. ${ }^{\mathrm{C}}$ Includes additional items

\section{Statistical analyses}

Prior to analyses, we will exclude participants based on the following criteria to decrease noise in online survey data: relative speed indicator higher than 2 , which means that the respondent has completed a page twice as fast as a typical respondent [70], and a completion time $<5$ min, which means an unrealistic absolute completion time. To deal with missing data and drop-out, multiple imputations via fully conditional specification implemented by the MICE algorithm will be used [71].

We will apply cross-lagged panel models to estimate the reciprocal relationships between a) resiliency and coping strategies and b) psychosocial adaptation and adjustment. Dependent measures will be checked for normality and then centered based on their grand mean. As a first step, we will conduct longitudinal confirmatory factor analyses (CFA) for each cohort ("inconspicuous"; "conspicuous"), using the covariance matrix. In a second step, we will specify longitudinal cross-lagged panel models with a) resiliency and coping strategies and b) psychosocial adaptation and adjustment as latent factors for each group. In a third step, we will conduct a multigroup analysis, which combines the models for both cohorts. In a fourth step, we will implement the covariates (e.g., age, gender) into the final models. In a final step, we will split latent predictors into their respective indicators examining the relations between a) resiliency and coping strategies and b) psychosocial adaptation and adjustment at the level of components.

Regression analyses will be applied to analyze the incremental/additional contribution of adaptation in psychosocial adjustment beyond the influence of general demographic and CC-related factors. HRQoL (total score and subscales' scores) will serve as dependent variable(s), the sociodemographic, CC-specific risk factors and the psychosocial adaptation will form the independent variables. The analysis on differences in a) resiliency and coping strategies and b) the psychosocial adaptation and adjustment depending on demographic and $\mathrm{CC}$ related factors will be addressed by three multifactorial ANOVAs. To examine differences in the course of psychosocial adaptation and psychosocial adjustment, 
multifactorial repeated measures ANOVAs will be applied. Before these analyses (Hypotheses 2-4), data will be checked on homoscedasticity, normal distribution of errors and multicollinearity. We will control for overall Covid-19 related distress for all analyses, if there is a significant association with psychosocial adjustment at $\mathrm{T} 1$ and/or T2. The analyses will be conducted using $\mathrm{R}$ [71-74].

\section{Discussion}

CCs are quite common among adolescents and can hinder their age-appropriate psychosocial development. So far, research has mainly focused on various risk factors for such an unfavorable development. The present study aims to undertake a paradigm shift in the research on CCs by explicitly focusing on the intrapersonal resources of those affected and a broad range of psychosocial adjustments. The present study aims to examine the reciprocal associations between resiliency and coping strategies (psychosocial adaptation) on the one hand and psychosocial adjustment on the other hand across a oneyear period in a sample of adolescents facing CCs. The findings will expand our current knowledge addressing the following aspects: (1) This study focuses on an assessment of resiliency factors and coping strategies in explaining psychosocial adjustment. Up to now, protective factors and their incremental contribution have been rarely addressed but provide unique starting points for preventional and interventional approaches; (2) A major strength is the inclusion and longer-term follow-up of youths in a sensitive developmental stage for the emergence of mental health problems, non-adherence and health-related risk behaviors [22]. Adolescence is considered to be the "cradle of health-related behaviors" and therefore provides great opportunities for maintaining and improving current and future health [22]; (3) The simultaneous consideration of specific CCs differing in various CC-related aspects (e.g., the role of pain; medical treatment or life-expectancy) follows a non-categorical approach [75]. By including CCs with diverse characteristics, one can identify the unique vs. generic characteristics in the process of psychosocial adaptation. Especially the identification of generic modifiable aspects will support the theory-driven development of non-categorical interventions, which is highly important for those adolescents with a rare condition [7]. (4) The broad recruitment via the German patient registries enables a representative sample. (5) We will include both, those adolescents facing problems in coping with their $\mathrm{CC}$ and those who are doing well. By ensuring that both subsamples are nearly comparable with respect to the sample size, we will be able to compare their respective resource profiles. In addition, the sample sizes will be large enough for applying multi-group comparisons over time.
(6) Using a comprehensive set of instruments, we can assess various aspects of psychosocial adaptation in the face of CCs (e.g., social support, self-compassion, and problem-solving skills). (7) The study takes an interdisciplinary approach: Medical data are linked to psychological parameters, thus allowing deeper insights into potential resilience effects on medical health parameters among others.

Possible obstacles and limitations are as follows: (1) A prospective study design bears the risk of a higher dropout, especially of those who show higher levels of emotional distress [76]. To minimize the risk of a selective drop-out, participants receive a monetary incentive, which will likely increase study adherence. In addition, we have established regular contact via short text messages over the course of the observation period to reinforce committment to the study [77]. (2) The Covid19 pandemic and particularly the first lockdown had an influence on our recruiting success because medical appointments were postponed or patients did not show up, some medical facilities had to take on other medical care tasks, etc. Furthermore, the Covid-19 pandemic posed an additional coping challenge for youths and will most likely have an impact on their psychosocial adaptation, as the pandemic elicits life events with uncertainty, ambiguity, and loss of control, each of which is known to trigger psychosocial distress, including anxiety, depression, and anger [78]. Especially individuals with CCs might experience more emotional distress than their "healthy" peers, as they are at high risk for severe Covid19 disease progress [79]. It can be assumed that intraand interpersonal resiliency factors also have a major influence on the adaptation when dealing with this situation. Therefore, we decided to monitor possible Covid19 pandemic effects by implementing an additional Covid-19 assessment. This will allow us to observe coping with a stressful life event and to examine its unique influence.

In conclusion, our study will contribute to a deeper understanding of the dynamic process of psychosocial adaptation when facing a CC. Based on the empirical data of this longitudinal observational study, tailored resource-based interventions supporting a positive adaptation in youths with a CC can be developed. Such intervention approaches are not only suitable for helping those adolescents who already face adjustment problems. They can also be applied to prevent them from developing in the first place.

\section{Abbreviations}

BFSC: Benefit finding scale for children; BSSS: Berlin social support scales; CC: Chronic condition; CERQ: Cognitive emotion regulation questionnaire; CF: Cystic fibrosis; CFA: Confirmatory factor analyses; cJADAS: Clinical juvenile arthritis disease activity score; $\mathrm{COACH}$ : Chronic conditions in adolescents: Implementation and evaluation of patient-centered collaborative healthcare; CODI: Coping with chronic health conditions; DCGM-37: DISABKIDS chronic 
generic module; ERQ: Emotion regulation questionnaire; DPV: National diabetes registry; FAS: Functionality appreciation scale; FEV1: Forced expiratory volume in $1 \mathrm{~S}$; FRKJ 8-16: Questionnaire of resources in childhood and youth; FSK-KJ: Questionnaire of social competences in children and adolescents; GAD-7: General anxiety disorder-scale; HbA1c: Hemoglobin A1c; HRQoL: Health-related quality of life; NPRD: National paediatric rheumatologic database; PHQ-9: Patient health questionnaire; PSS4: Perceived stress scale; Q: Question; SAM: Self-assessment manikin; SCSD: Self-compassion scale; SCS-K-D: Self-control scale; SEM: Structural equation modeling; SSKJ 3-8: Questionnaire of stress and stress management in childhood and adolescence; SWLS: Satisfaction with life scale; WHO-5: WHO5 well-being index; T1: Measurement time point 1; T2: Measurement time point 2

\section{Supplementary Information}

The online version contains supplementary material available at https://doi. org/10.1186/s12887-021-02869-9.

Additional file 1:. Self-constructed study measures.

Additional file 2:. Measures for assessment of Covid-19-related factors.

\section{Acknowledgements}

Reinhold Kilian (Ulm University), and Thomas Meissner (Düsseldorf University) contributed to the study design. We acknowledge the support of the Deutsche Forschungsgemeinschaft and Open Access Publishing Fund of University of Potsdam.

\section{Authors' contributions}

$\mathrm{RH}, \mathrm{KM}, \mathrm{DS}$, and PW initiated the joint project and $F B, H B, R H, K M, D S, P W$, and RvR contributed to its design. PW designed the study. PW, FB, and RvR are responsible for the realization of the present study. FB, $A P, R \vee R$, and $P W$ wrote the draft of this manuscript. FB, HB, RH, AMS, KM, AP, CR, RvR, DS, and PW contributed to the further writing and approved the final manuscript. PW is its guarantor.

\section{Funding}

This study is realized as part of the joint project "Chronic Conditions in Adolescents: Implementation and Evaluation of Patient-centred Collaborative Healthcare $(\mathrm{COACH})$ ", funded by the German Federal Ministry of Education and Research (Grant No: 01GL1740C). The Federal Ministry of Education and Research provided feedback on the proposal of the study through an external peer-review process which was the basis for the final decision of funding the $\mathrm{COACH}$-project. The funding organization played no role in the study design, the collection, analysis, interpretation of data, nor in writing the protocol. Open Access funding enabled and organized by Projekt DEAL.

\section{Availability of data and materials}

Fully anonymized data will be available from the corresponding author on reasonable request and with the permission of the collaboration partners.

\section{Declarations}

\section{Ethics approval and consent to participate}

The study will be conducted in accordance with the principles of Good Clinical Practice, the Declaration of Helsinki (https://www.wma.net/ wpcontent/uploads/2016/11/DoH-Oct2008.pdf), and current ethical standards. Written informed consent is obtained from each participant. Depending on the age of the participant, informed consent from the legal representative or guardian will also be required. The central ethical approval of the Ethics Committee of Potsdam University was obtained (request numbers 52/2017, 37/2018, 27/2020, and 48/2020).

\section{Consent for publication}

Not applicable.

\section{Competing interests}

The authors declare that they have no competing interests.

\section{Author details}

${ }^{1}$ Department of Psychology, Counseling Psychology, University of Potsdam, Karl-Liebknecht-Str. 24-25, 14476 Potsdam, Germany. ${ }^{2}$ Department of Clinical Psychology and Psychotherapy, Faculty of Engineering, Computer Science and Psychology, Institute of Psychology and Education, UIm University, Ulm, Germany. ${ }^{3}$ Institute of Epidemiology and Medical Biometry, ZIBMT, UIm University, Ulm, Germany. ${ }^{4}$ Charité University Medicine Berlin, Berlin, Germany. ${ }^{5}$ German Rheumatism Research Centre, Berlin, Germany. ${ }^{6}$ Department of Psychiatry and Psychotherapy II, BKH Günzburg, UIm University, Günzburg, Germany. ${ }^{7}$ Department of General Pediatrics, Neonatology and Pediatric Cardiology, University Hospital Düsseldorf, Düsseldorf, Germany. ${ }^{8}$ Department of Pediatric Pulmonology, Immunology and Intensive Care Medicine, Charité University Medicine Berlin, Berlin, Germany.

Received: 12 July 2021 Accepted: 30 August 2021

Published online: 14 September 2021

\section{References}

1. Warschburger P. Health psychology in childhood. In: Wright J, editor. International encyclopedia of the social \& behavioral sciences: Elsevier; 2015. p. 679-85.

2. Reich W, Earls F. Rules for making psychiatric diagnoses in children on the basis of multiple sources of information: preliminary strategies. J Abnorm Child Psychol. 1987;15(4):601-16. https://doi.org/10.1007/BF00917244.

3. de Ridder D, Geenen R, Kuijer R, van Middendorp H. Psychological adjustment to chronic disease. Lancet. 2008;372(9634):246-55. https://doi. org/. https://doi.org/10.1016/S0140-6736(08)61078-8.

4. Habib AR, Manji J, Wilcox PG, Javer AR, Buxton JA, Quon BS. A systematic review of factors associated with health-related quality of life in adolescents and adults with cystic fibrosis. Ann Am Thorac Soc. 2015;12(3):420-8. https:// doi.org/10.1513/AnnalsATS.201408-3930C.

5. Nieuwesteeg A, Pouwer F, van der Kamp R, van Bakel H, Aanstoot H-J, Hartman E. Quality of life of children with type 1 diabetes: a systematic review. Curr Diabetes Rev 2012;8:434-443. https://doi.org/https://doi.org/1 $0.2174 / 157339912803529850,6$.

6. Varni JW, Limbers CA, Burwinkle TM. Impaired health-related quality of life in children and adolescents with chronic conditions: A comparative analysis of 10 disease clusters and 33 disease categories/severities utilizing the PedsQL 4.0 Generic Core Scales. Health Qual Life Outcomes. 2007:5:43-57. https://doi.org/https://doi.org/10.1186/1477-7525-5-43.

7. Warschburger P. Chronisch kranke Kinder und Jugendliche. Psychosoziale Belastungen und Bewältigungsanforderungen. Göttingen: Hogrefe; 2000.

8. Lavigne JV, Faier-Routman J. Psychological adjustment to pediatric physical disorders: a meta-analytic review. J Pediatr Psychol. 1992;17(2):133-57. https://doi.org/10.1093/jpepsy/17.2.133.

9. Pinquart $M$, Shen $Y$. Behavior problems in children and adolescents with chronic physical illness: a meta-analysis. J Pediatr Psychol 2011;36:10031016. https://doi.org/https://doi.org/10.1093/jpepsy/jsr042, 9.

10. Pinquart $M$, Shen $Y$. Depressive symptoms in children and adolescents with chronic physical illness: an updated meta-analysis. J Pediatr Psychol 2011;36: 375-384. https://doi.org/https://doi.org/10.1093/jpepsy/jsq104, 4.

11. Compas BE, Jaser SS, Dunn MJ, Rodriguez EM. Coping with chronic illness in childhood and adolescence. Annu Rev Clin Psychol 2012:8:455-480. https:// doi.org/https://doi.org/10.1146/annurev-clinpsy-032511-143108, 1.

12. Lavigne JV, Faier-Routman J. Correlates of psychological adjustment to pediatric physical disorders: a meta-analytic review and comparison with existing models. J Dev Behav Pediatr. 1993;14(2):117-23.

13. Thompson RJ, Gustafson KE. Adaptation to chronic childhood illness. Washington: American Psychological Association; 1996. https://doi.org/10.1 037/10188-000

14. Cousins LA, Kalapurakkel S, Cohen LL, Simons LE. Topical review: resilience, resources and mechanisms in pediatric chronic pain. J Pediatr Psychol 2015; 40:840-845. https://doi.org/https://doi.org/10.1093/jpepsy/jsv037, 9.

15. Hilliard ME, Harris MA, Weissberg-Benchell J. Diabetes resilience: a model of risk and protection in type 1 diabetes. Curr Diab Rep 2012;12:739-748. https://doi.org/https://doi.org/10.1007/s11892-012-0314-3, 6.

16. Fuhrer U. Jugendalter: Entwicklungsriskiken und Entwicklungsabweichungen. In: Petermann F, editor. Lehrbuch der Klinischen Kinderpsychologie. 7th ed. Göttingen: Hogrefe; 2013. p. 119-33. 
17. Cramm JM, Strating MM, Nieboer AP. The importance of general selfefficacy for the quality of life of adolescents with diabetes or juvenile rheumatoid arthritis over time: a longitudinal study among adolescents and parents. Front Pediatr 2013;1(40);1-8. https://doi.org/https://doi.org/10.3389/ fped.2013.00040

18. Cramm JM, Strating MMH, Roebroeck ME, Nieboer AP. The importance of general self-efficacy for the quality of life of adolescents with chronic conditions. Soc Indic Res 2013;113:551-561. https://doi.org/https://doi.org/1 0.1007/s11205-012-0110-0, 1.

19. Pinquart M. Self-esteem of children and adolescents with chronic illness: a meta-analysis. Child Care HIth Dev 2013;39:153-161. https://doi.org/https:// doi.org/10.1111/j.1365-2214.2012.01397.x, 2.

20. Helgeson VS, Reynolds KA, Tomich PL. A meta-analytic review of benefit finding and growth. J Consult Clin Psychol 2006;74:797-816. https://doi.org/ https://doi.org/10.1037/0022-006X.74.5.797, 5.

21. Turner-Cobb J. Child health psychology: a biopsychosocial perspective. Los Angeles: Sage; 2013.

22. Sawyer SM, Afifi RA, Bearinger LH, Blakemore S-J, Dick B, Ezeh AC, Patton GC Adolescence: A foundation for future health. Lancet. 2012;379:1630-1640. https://doi.org/ https://doi.org/10.1016/S0140-6736(12)60072-5, 9826.

23. Sowislo JF, Orth U. Does low self-esteem predict depression and anxiety? A meta-analysis of longitudinal studies. Psychol Bull 2013;139:213-240. https:// doi.org/ https://doi.org/10.1037/a0028931, 1.

24. Livneh H, Antonak RF. Psychosocial adaptation to chronic illness and disability. Gaithersburg, MD: Aspen; 1997.

25. Lunkenheimer F, Domhardt M, Geirhos A, Kilian R, Mueller-Stierlin AS, Holl RW, Meissner T, Minden K, Moshagen M, Ranz R, Sachser C, Staab D, Warschburger $\mathrm{P}$, Baumeister $\mathrm{H}$. Effectiveness and cost-effectiveness of guided internet- and mobile-based CBT for adolescents and young adults with chronic somatic conditions and comorbid depression and anxiety symptoms (youthCOACH $\mathrm{CD}_{\mathrm{CD}}$ ): study protocol for a multicentre randomized controlled trial. Trials. 2020;21:253. https://doi.org/https://doi.org/10.1186/s13 063-019-4041-9, 1.

26. Reinauer C, Viermann R, Förtsch K, Linderskamp H, Warschburger P, Holl RW, Staab D, Minden K, Muche R, Domhardt M, Baumeister H, Meissner T. Motivational Interviewing as a tool to enhance access to mental health treatment in adolescents with chronic medical conditions and need for psychological support (COACH-MI): study protocol for a clusterrandomised controlled trial. Trials. 2018;19:629. ttps://doi.org/https://doi.org/10.1186/s13 063-018-2997.

27. Allgaier AK, Pietsch K, Frühe B, Sigl-Glöckner J, Schulte-Körne G. Screening for depression in adole-scents: validity of the patient health questionnaire in pediatric care. Depress Anxiety 2012;29(10):906-913. https://doi.org/https:// doi.org/10.1002/da.21971Epub2012Jul2.

28. Hinz A, Klein AM, Brähler E, Glaesmer H, Luck T, Riedel-Heller SG, Wirkner K,Hilbert A. Psychometric evaluation of the generalized anxiety disorder screener GAD-7, based on a large German general population sample. J Affect Disord 2017;210: 338-344. https://doi.org/https://doi.org/10.1016/j.jad.2016.12.012.

29. Plummer F, Manea L, Trepel D, McMillan D. Screening for anxiety disorders with the GAD-7 and GAD-2: a systematic review and diagnostic metaanalysis. Gen Hosp Psychiatry 2016;39;24-31. https://doi.org/ https://doi. org/10.1016/j.genhosppsych.2015.11.005.

30. Richardson LP, McCauley E, Grossman DC, McCarty CA, Richards J,Russo JE, Rockhill C, Katon W. Evaluation of the patient health Questionnaire-9 item for detecting major depression among adolescents. Pediatrics. 2010;126(6): 1117-1123. https://doi.org/https://doi.org/10.1542/peds.2010-0852.

31. Zhong QY, Gelaye B, Zaslavsky AM, Fann JR, Rondon MB, Sánchez SE,Williams MA. Diagnostic validity of the generalized anxiety Disorder-7 (GAD-7) among pregnant women. PLoS One 2015;10(4):e0125096. https:// doi.org/https://doi.org/10.1371/journal.pone.0125096.

32. Minden K, Niewerth M, Listing J, Zink A. German study Group of Pediatric Rheumatologists. Health care provision in pediatric rheumatology in Germany--national rheumatologic database. J Rheumatol. 2002;29(3):622-8.

33. Hofer SE, Schwandt A, Holl RW. Standardized documentation in pediatric diabetology: experience from Austria and Germany. J Diabetes Sci Technol 2016; 10:1042-1049. https://doi.org/https://doi.org/10.1177/1932296816658057, 5.

34. Stern M. The use of a cystic fibrosis patient registry to assess outcomes and improve cystic fibrosis care in Germany. Curr Opin Pulm Med 2011;17;473477. https://doi.org/https://doi.org/10.1097/MCP.0b013e32834b6b72, 6

35. Schmidt S. The DISABKIDS questionnaires: quality of live questionnaires for children with chronic conditions. Lengerich: Pabst Science Publ; 2006.
36. World Health Organization. WHO (Fünf). Fragebogen zum Wohlbefinden: Psychiatric Research Unit, WHO Collaborating Center for Mental Health, Frederiksborg General Hospital, DK-3400 Hillerød; 1998.

37. Allgaier AK, Pietsch K, Frühe B, Prast E, Sigl-Glöckner J, Schulte-Körne G. Depression in pediatric care: is the WHO-five well-being index a valid screening instrument for children and adolescents? Gen Hosp Psychiat. 2012;34(3):234-41. https://doi.org/10.1016/j.genhosppsych.2012.01.007.

38. Janke S, Glöckner-Rist A. Deutsche Version der Satisfaction with Life Scale (SWLS). In: Zusammenstellung sozialwissenschaftlicher Items und Skalen (ZIS); 2012.

39. Glaesmer H, Grande G, Braehler E, Roth M. The German version of the satisfaction with life scale (SWLS). Eur J Psychol Assess 2011;27(2): 127-132. https://doi.org/https://doi.org/10.1027/1015-5759/a000058.

40. Bradley MM, Lang PJ. Measuring emotion: the self-assessment manikin and the semantic differential. J Behav Ther Exp Psy 1994;25(1):49-59. https://doi. org/https://doi.org/10.1016/0005-7916(94)90063-9.

41. Lang P. Behavioral treatment and bio-behavioral assessment: Computer applications. In: Technology in mental health care delivery systems. Nordwood: Ablex Publishing; 1980. p. 119-37.

42. Lohaus A, Nussbeck FW. FRKJ-8-16. In: Fragebogen zu Ressourcen im Kindes- und Jugendalter. Göttingen: Hogrefe; 2016.

43. Jurkowski S, Hänze M. Diagnostik sozialer Kompetenzen bei Kindern und Jugendlichen. Diagnostica. 2014;60:167-180. https://doi.org/https://doi.org/1 0.1026/0012-1924/a000104, 4

44. Schulz U, Schwarzer R. Soziale Unterstützung bei der Krankheitsbewältigung: Die Berliner Social Support Skalen (BSSS). Diagnostica. 2003;49(2):73-82. https://doi.org/10.1026//0012-1924.49.2.73.

45. Bertrams A, Dickhäuser O. Messung dispositioneller Selbstkontroll-Kapazität: Eine deutsche Adaptation der Kurzform der Self-Control Scale (SCS-K-D). Diagnostica. 2009;55:2-10. https://doi.org/https://doi.org/10.1026/0012-1924. 55.1.2, 1.

46. Hupfeld J, Ruffieux N. Validierung einer deutschen Version der SelfCompassion Scale (SCS-D). Z Klin Psychol Psychother 2011;40:115-123. https://doi.org/https://doi.org/10.1026/1616-3443/a000088, 2

47. Raes F, Pommier E, Neff KD, van Gucht D. Construction and factorial validation of a short form of the self-compassion scale. Clin Psychol Psychother 2011;18:250-255. https://doi.org/ https://doi.org/10.1002/ cpp.702, 3.

48. Alleva JM, Tylka TL, van Kroon Diest AM. The functionality appreciation scale (FAS): development and psychometric evaluation in U.S. community women and men. Body Image 2017;23:28-44. https://doi.org/https://doi. org/10.1016/j.bodyim.2017.07.008.

49. Petersen C, Schmidt S, Bullinger M. Brief report: development and pilot testing of a coping questionnaire for children and adolescents with chronic health conditions. J Pediatr Psychol 2004;29:635-640. https://doi.org/ https://doi.org/10.1093/jpepsy/jsh066, 8

50. Lohaus A, Eschenbeck H, Kohlmann C-W, Klein-Heßling J. Fragebogen zur Erhebung von Stress und Stressbewältigung im Kindes- und Jugendalter (SSKJ 3-8). Göttingen: Hogrefe; 2006.

51. Abler B, Kessler H. Emotion Regulation Questionnaire - Eine deutschsprachige Fassung des ERQ von Gross und John. Diagnostica. 2009; 55:144-152. https://doi.org/https://doi.org/10.1026/0012-1924.55.3.144, 3.

52. Loch N, Hiller W, Witthöft M. Der Cognitive Emotion Regulation Questionnaire (CERQ). Z KI Psych Psychoth 2011;40:94-106. https://doi.org/ https://doi.org/10.1026/1e616-3443/a000079, 2.

53. Garnefski N, Kraaij V. Cognitive emotion regulation questionnaire development of a short 18-item version (CERQ-short). Pers Indiv Differ 2006; 41:1045-1053. https://doi.org/https://doi.org/10.1016/j.paid.2006.04.010, 6.

54. Phipps S, Long AM, Ogden J. Benefit finding scale for children: preliminary findings from a childhood cancer population. J Pediatr Psychol 2007;32: 1264-1271. https://doi.org/https://doi.org/10.1093/jpepsy/jsl052, 10.

55. Löwe B, Spitzer RL, Zipfel S, Herzog W. Gesundheitsfragebogen für Patienten (PHQ-D). 2nd ed. Karlsruhe: Pfizer; 2002.

56. Erbe D, Eichert $\mathrm{H}-\mathrm{C}$, Rietz $\mathrm{C}$, Ebert D. Interformat reliability of the patient health questionnaire: validation of the computerized version of the PHQ-9. Internet Interv 2016:5:1-4. https://doi.org/https://doi.org/10.1016/j.invent.201 6.06.006.

57. Löwe B, Decker O, Müller S, Brähler E, Schellberg D, Herzog W, Herzberg PY Validation and standardization of the generalized anxiety disorder screener (GAD-7) in the general population. Med Care 2008:46:266-274. https://doi. org/https://doi.org/10.1097/MLR.0b013e318160d093, 3. 
58. Spitzer RL, Kroenke K, Williams JBW, Löwe B. A brief measure for assessing generalized anxiety disorder: the GAD-7. Arch Intern Med 2006;166:10921097. https://doi.org/https://doi.org/10.1001/archinte.166.10.1092, 10.

59. Dear BF, Titov N, Sunderland M, McMillan D, Anderson T, Lorian C, Robinson E Psychometric comparison of the generalized anxiety disorder scale-7 and the Penn State worry questionnaire for measuring response during treatment of generalised anxiety disorder. Cogn Behav Ther 2011;40(3):216227. https://doi.org/https://doi.org/10.1080/16506073.2011.582138.

60. Fox CK, Gross AC, Rudser KD, Foy AMH, Kelly AS. Depression, anxiety, and severity of obesity in adolescents: is emotional eating the link? Clin Pediatr 2016;55(12):1120-1125. https://doi.org/https://doi.org/10.1177/000992281561 5825.

61. Puka K, Widjaja E, Smith ML. The influence of patient, caregiver, and family factors on symptoms of anxiety and depression in children and adolescents with intractable epilepsy. Epilepsy Behavior 2017;67;45-50. https:/doi.org/ https://doi.org/10.1016/j.yebeh.2016.12.011.

62. Dreher $\mathrm{E}$, Dreher M. Fragebogen zu Entwicklungsaufgaben im Jugendalter. 5th ed. München: Ludwig-Maximilians-Universität München; 2009.

63. Cohen S, Kamarck T, Mermelstein R. A global measure of perceived stress. J Health Soc Behav 1983;24:385-396. https://doi.org/https://doi.org/10.23 07/2136404, 4.

64. Hölling H, Schlack R, Kamtsiuris P, Butschalowsky H, Schlaud M, Kurth BM. Die KiGGS-Studie. Bundesgesundheitsbla. 2012;55:836-842. https://doi.org/ https://doi.org/10.1007/s00103-012-1486-3, 6-7.

65. Schorlemmer J. Typische und atypische Berufswünsche nach Geschlecht und sozioökonomischem Status. Die Bedeutung von Selbst, Leistung, Motivation und Volition für individuelle Passungsprozesse bei Kindern und Jugendlichen. Unveröffentlichte Dissertation; 2015.

66. Bullinger M, Kirchberger I. Der SF-36-Fragebogen zum Gesundheitszustand. In: Handbuch für die deutschsprachige Fragebogenversion. Göttingen: Hogrefe; 1997.

67. Eriksson I, Undén A-L, Elofsson S. Self-rated health. Comparisons between three different measures. Results from a population study. Int J Epidemiol 2001;30:326-333. https://doi.org/https://doi.org/10.1093/ije/30.2.326, 2 .

68. van Dick R. Stress lass nach!: Wie Gruppen unser Stresserleben beeinflussen. Berlin: Springer Spektrum; 2015.

69. Kline RB. Principles and practice of structural equation modeling. 4th ed. New York: Guilford Press; 2016.

70. Leiner DJ. Too fast, too straight, too weird: non-reactive indicators for meaningless data in internet surveys. Surv Res Methods 2019;13(3);229-248. https://doi.org/https://doi.org/10.18148/srm/2019.v13i3.7403

71. van Buuren S, Groothuis-Oudshoorn K. Mice: multivariate imputation by chained equations in R. J Stat Soft 2011;45(3);1-67. https://doi.org/https:// doi.org/10.18637/jss.v045.103

72. R Core Team. R: a language and environment for statistical computing. R Foundation for statistical Computing; 2020. https://www.R-project.org/

73. Revelle W. Psych: Procedures for psychological, psychometric, and personality research. R package version. 2021:1-412.

74. Rosseel Y. Lavaan: an R package for structural equation modeling. J Stat Softw 2012:48(2):1-37. https://doi.org/https://doi.org/10.18637/jss.v048.i02.

75. Stein REK, Jessop DJ. A noncategorical approach to chronic childhood illness. Public Health Rep. 1982;97(4):354-62.

76. Warschburger $P$, Kröller K. Loss to follow-up in a randomized controlled trial study for pediatric weight management (EPOC). BMC Pediatr. 2016;16(1):1-9.

77. Teague S, Youssef GJ, Macdonald JA, Sciberras E, Shatte A, Fuller-Tyszkiewicz M, Greenwood C, McIntosh J, Olsson CA, Hutchinson D, SEED Lifecourse sciences theme. Retention strategies in longitudinal cohort studies: a systematic review and meta-analysis. BMC Med Res Methodol 2018;18(1);122. https://doi.org/https://doi.org/10.1186/s12874-018-0586-7.

78. Shanahan L, Steinhoff A, Bechtiger L, Murray AL, Nivette A, Hepp U, Ribeaud D, Eisner M. Emotional distress in young adults during the COVID-19 pandemic: evidence of risk and resilience from a longitudinal cohort study. Psychol Med 2020;1-10. https://doi.org/https://doi.org/10.1017/S003329172000241X.

79. Alonzi S, La Torre A, Silverstein MW. The psychological impact of preexisting mental and physical health conditions during the COVID-19 pandemic. Psychol Trauma Theory Res Pract Policy 2020;51;236-238. http://dx.doi.org/ https://doi.org/10.1037/tra0000840, S1.

\section{Publisher's Note}

Springer Nature remains neutral with regard to jurisdictional claims in published maps and institutional affiliations.

\section{Ready to submit your research? Choose BMC and benefit from:}

- fast, convenient online submission

- thorough peer review by experienced researchers in your field

- rapid publication on acceptance

- support for research data, including large and complex data types

- gold Open Access which fosters wider collaboration and increased citations

- maximum visibility for your research: over $100 \mathrm{M}$ website views per year

At BMC, research is always in progress.

Learn more biomedcentral.com/submissions 